\title{
Preliminary exploration of the air quality of SRYYL in Qinghai Province
}

\author{
Deping Zhao ${ }^{1, a}$, Xun $\mathrm{Xu}^{2,4,5, b^{*}}$, Xudong Zhao ${ }^{3,4,5, \mathrm{c}}$, Xiaoyan Dou ${ }^{4, \mathrm{~d}}$,Yanfeng $\mathrm{Li}^{4, \mathrm{e}}$ \\ ${ }^{1}$ Northwest Plateau Institute of Biology; The Chinese Academy of Sciences; Xining 810001,China. \\ ${ }^{2}$ Environmental science and engineering college of Shandong University, ShangDong \\ 250000 ,China.
}

${ }^{3}$ College of Environmental Science and Engineering of Nankai University, Tianjin 300071, China.

${ }^{4}$ Environmental monitoring center of Qinghai province, Qinghai 810000,China.

${ }^{5}$ National Station for Background Atmospheric Monitoring, Menyuan, Qinghai, China

adpzhao@nwipb.cas.cn, ${ }^{\text {b. }}$ xxmisssj@163.com, ${ }^{\mathrm{c}}$ zhao_xu_dong@163.com,

dd.xy@163.com, e'Liyanfeng@163.com

*Corresponding author : xxmisssj@163.com

Keywords: air quality, SRYYL, National Station for Background Atmospheric Monitoring, Menyuan, Qinghai, China, Variation , Preliminary exploration

\begin{abstract}
The source region of the Yangtze River, Yellow River and Lancang River is the one of the most important ecological area around the world which have significant impact on the watershed. Since the related River is the mother river of Chinese, the air quality at the source region is more important than other region due to possible pollutant deposition, the damage to plants and so on. We analyzed the automatic monitoring data to show the air quality of the source region of the Yangtze river, Yellow river and Lancang river (SRYYL) and preliminary explore the air quality of the SRYYL.
\end{abstract}

\section{Introduction}

The source region of the Yangtze River, Yellow River and Lancang River locates in Yus hu State Guoluo State and Huangnan State of Qinghai province. The government have set $\mathrm{u}$ $\mathrm{p}$ three air automatic monitoring stations in these three states in 2014. We collected the air quality data from the stations was reported to the government from January $1^{\text {st }}, 2015$. In $\mathrm{t}$ his report, we reported the air quality data from January to July, which was the most pollu ted seasons due to heavy dust storms and anthropogenic emissions.

\section{Sources of data and research methods}

\section{Air quality data}

In this study, the data was collected from 3 stations located in Yushu State, Guoluo State, and Huangnan State air quality automatic monitoring station in Qinghai, China. The measu rement includes $\mathrm{SO}_{2} \mathrm{NO}_{2} \mathrm{PM}_{10} \mathrm{PM}_{2.5} \mathrm{CO}$ and $\mathrm{O}_{3}$, which was checked and accepted by $\mathrm{Ch}$ ina Environmental Monitoring Station. With careful maintenance, the data could reflect of th e air quality of the SRYYL. 


\section{Research methods}

Continuous measurements on $\mathrm{SO}_{2} \mathrm{NO}_{2} \mathrm{PM}_{10} \mathrm{PM}_{2.5} \mathrm{CO}$ and $\mathrm{O}_{3}$ were carried out in these three state from January to July in 2015, the variation and relationship were discussed det ailedly. Then, we explored the preliminary reasons and obtained the rule of pollution evoluti on, which could be an feasible indicator of future pollution predictions and policy decision S..

\section{Apparatus}

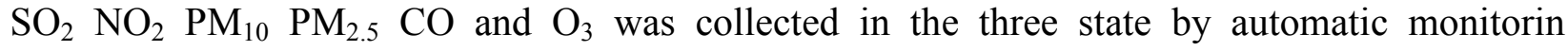
$\mathrm{g}$ station. All of data were measured between 0 and $2000 \mathrm{mg} / / 1$, the limit of detection is 0.2 $\mathrm{mg} / \mathrm{l}$.

\section{Result}

\section{Average concentration of six main pollutants}

Table1.The average concentration of six main pollutants

\begin{tabular}{|l|c|c|c|c|c|c|}
\hline Yushu & $\begin{array}{c}\mathrm{SO}_{2} \\
{\left[\mu \mathrm{g} / \mathrm{m}^{3}\right]}\end{array}$ & $\begin{array}{c}\mathrm{NO}_{2} \\
{\left[\mu \mathrm{g} / \mathrm{m}^{3}\right]}\end{array}$ & $\begin{array}{c}\mathrm{CO} \\
{\left[\mathrm{mg} / \mathrm{m}^{3}\right]}\end{array}$ & $\begin{array}{c}\mathrm{O}_{3} \\
{\left[\mu \mathrm{g} / \mathrm{m}^{3}\right]}\end{array}$ & $\begin{array}{c}\mathrm{PM}_{10} \\
{\left[\mu \mathrm{g} / \mathrm{m}^{3}\right]}\end{array}$ & $\begin{array}{c}\mathrm{PM}_{2.5} \\
{\left[\mu \mathrm{g} / \mathrm{m}^{3}\right]}\end{array}$ \\
\hline Guoluo & 24.05 & 18.91 & 0.83 & 91.71 & 52.76 & 24.60 \\
\hline Huangnan & 23.82 & 13.47 & 0.48 & 104.40 & 102.48 & 45.13 \\
\hline
\end{tabular}

In Table1 from January to July, the average concentration of $\mathrm{SO}_{2}$ were $24.05 \mu \mathrm{g} / \mathrm{m} 3,23$. $82 \mu \mathrm{g} / \mathrm{m}^{3}, 21.13 \mu \mathrm{g} / \mathrm{m}^{3}$ in Yushu Guoluo and Huangnan State, the concentration of $\mathrm{NO}_{2}$ were $18.91 \mu \mathrm{g} / \mathrm{m}^{3} 13.47 \mu \mathrm{g} / \mathrm{m}^{3} 14.43 \mu \mathrm{g} / \mathrm{m}^{3}$, the concentration of $\mathrm{CO}$ were $0.83 \mathrm{mg} / \mathrm{m}^{3} 0.48 \mathrm{mg} / \mathrm{m}^{3} 0$. $81 \mathrm{mg} / \mathrm{m}^{3}$, the concentration of $\mathrm{O}_{3}$ were $91.91 \mu \mathrm{g} / \mathrm{m}^{3} 104.40 \mu \mathrm{g} / \mathrm{m}^{3} 95.51 \mu \mathrm{g} / \mathrm{m}^{3}$, the concentrati on of $\mathrm{PM}_{10}$ were $52.76 \mu \mathrm{g} / \mathrm{m}^{3} 102.48 \mu \mathrm{g} / \mathrm{m}^{3}$ and $139.18 \mu \mathrm{g} / \mathrm{m}^{3}$, the concentration of $\mathrm{PM}_{10}$ wer e $24.60 \mu \mathrm{g} / \mathrm{m}^{3} 45.13 \mu \mathrm{g} / \mathrm{m}^{3} 58.80 \mu \mathrm{g} / \mathrm{m}^{3}$. The concentration of $\mathrm{O}_{3}$ of the SRYYL is higher tha $\mathrm{n}$ other place, the concentration of $\mathrm{PM}_{10}$ and $\mathrm{PM}_{2.5}$ of Huangnan State was the highest in $\mathrm{t}$ he three place and in Guoluo State was higher. And the concentration in Guoluo and Huan gnan State is higher than national standard of $\mathrm{PM}_{10}$ and $\mathrm{PM}_{2.5}$.

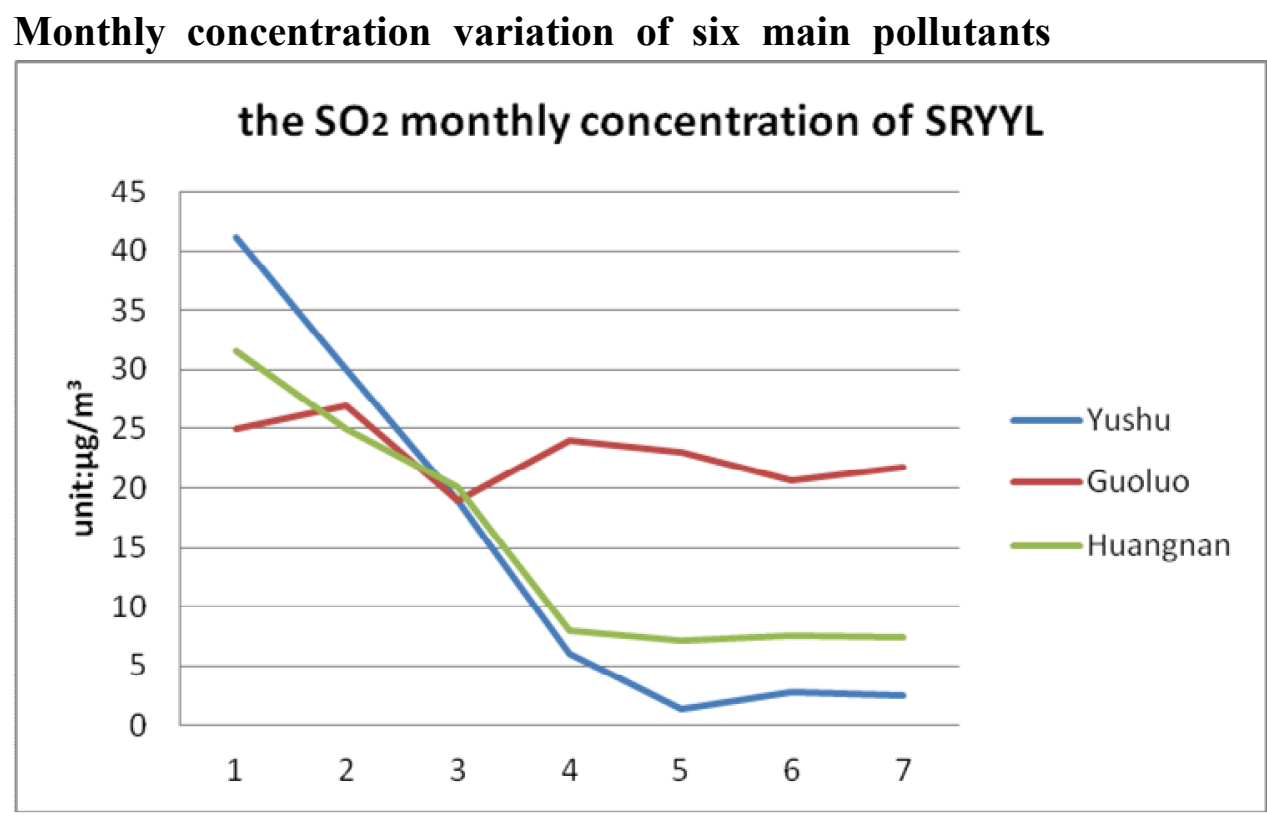

Fig.1 The $\mathrm{SO}_{2}$ monthly concentration of SRYYL

The $\mathrm{SO}_{2}$ monthly concentration of SRYYL is higher in January and February then decrea sed rapidly showing a significant impact of coal consumption in winter. The concentration $\mathrm{O}$ 
f $\mathrm{SO}_{2}$ reached the lowest point during May and June. Then continued a low level at Yushu and Huangnan. However, the $\mathrm{SO}_{2}$ concentration increased at April didn't change much duri ng the rest months at Guoluo station. The steady pattern of $\mathrm{SO}_{2}$ in Guoluo shows clearly $\mathrm{u}$ nknown sources.

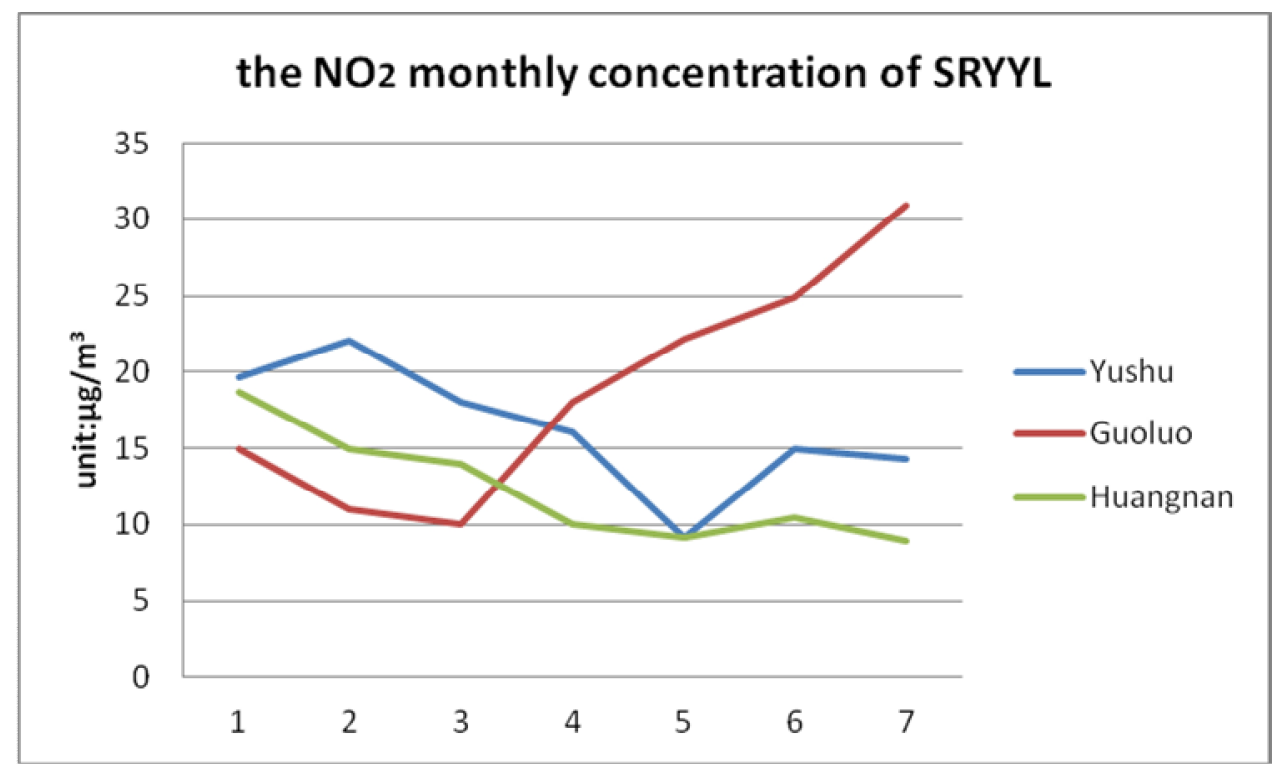

Fig. 2 The $\mathrm{NO}_{2}$ monthly concentration of SRYYL

The $\mathrm{NO}_{2}$ monthly concentration of SRYYL is higher in January and February then decre ased rapidly, but in Guoluo State, the concentration increased from march to July. Consideri ng there are source also for $\mathrm{SO}_{2}$ during the summer in Guoluo, it should largely related to human activities. The lowest point showed in May. The overall level of the concentration of $\mathrm{NO}_{2}$ is under the national standard.

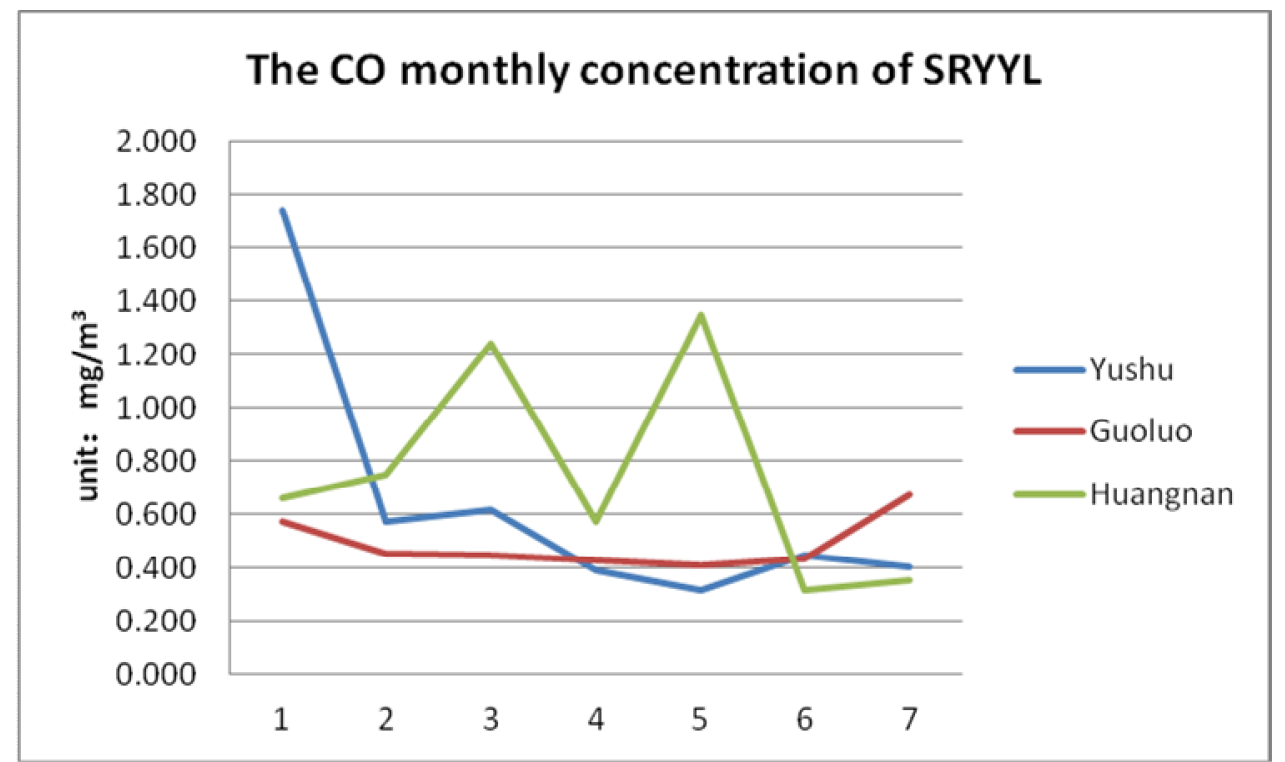

Fig.3 The CO monthly concentration of SRYYL

The CO monthly concentration of Yushu is different in January and February then decrea sed rapidly, but in Guoluo State, the concentration increased when April came and decrease d slowly. The concentration of $\mathrm{SO}_{2}$ reached the lowest point during May and June. Then it continued a low level. 


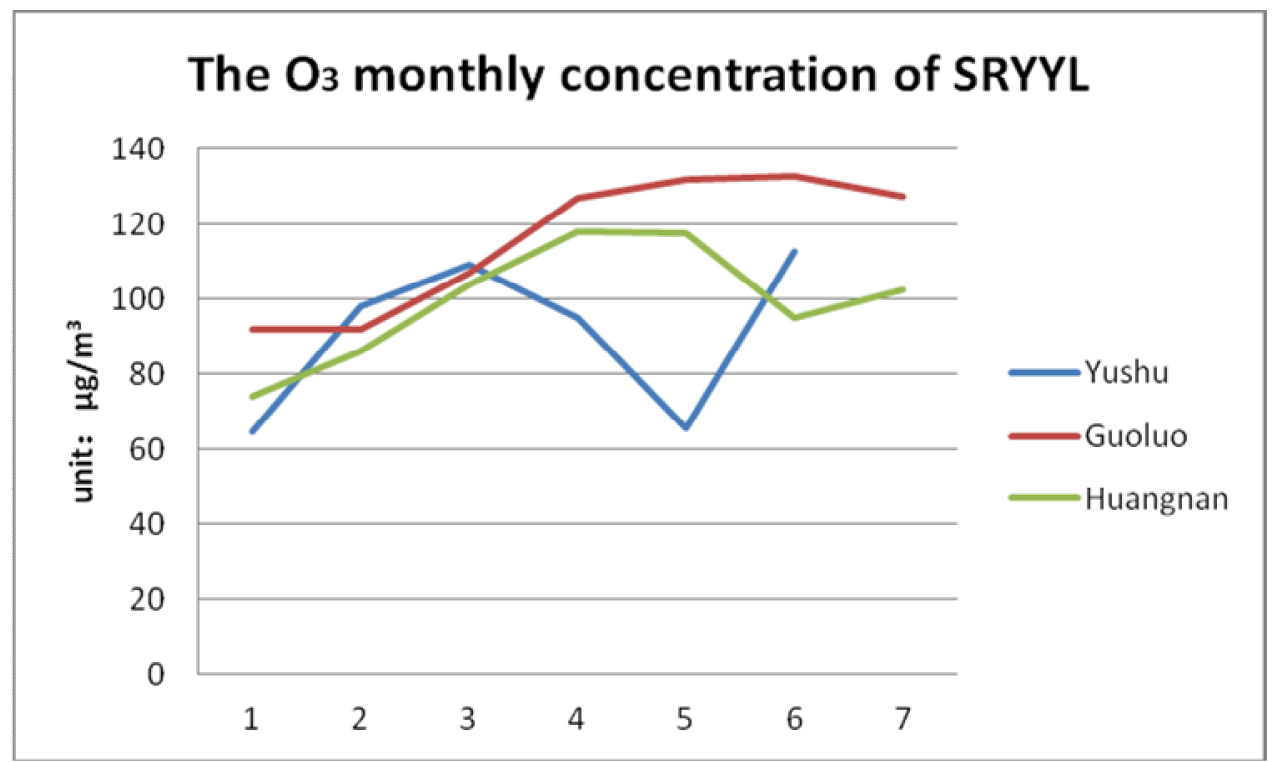

Fig.4 The $\mathrm{O}_{3}$ monthly concentration of SRYYL

The $\mathrm{O}_{3}$ should be most concerned about, monthly concentration of the three state was all showed an ascending trend from January to July, the Guoluo State was the most obvious. The Yushus' went down starting from March and increasing rapidly from May. They all rea ch the highest point during June and July.

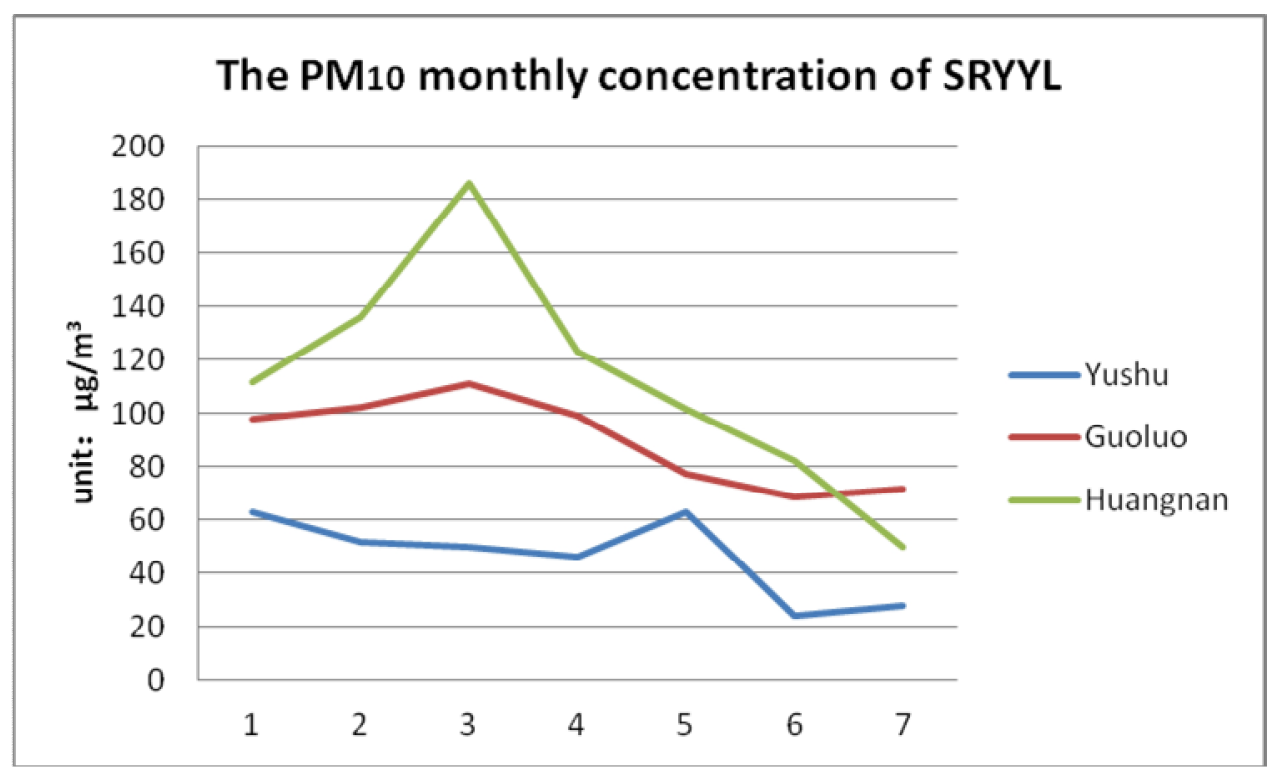

Fig.5 The $\mathrm{PM}_{10}$ monthly concentration of SRYYL

The $\mathrm{PM}_{10}$ maybe the most important pollutants in the SRYYL, in the Winter and Spring monthly concentration of the three state were higher than any other months due to strong spring dust storms. In the three states, Huangnan State's concentration is the highest. They all decrease from April and reach the lowest point during June and July. 


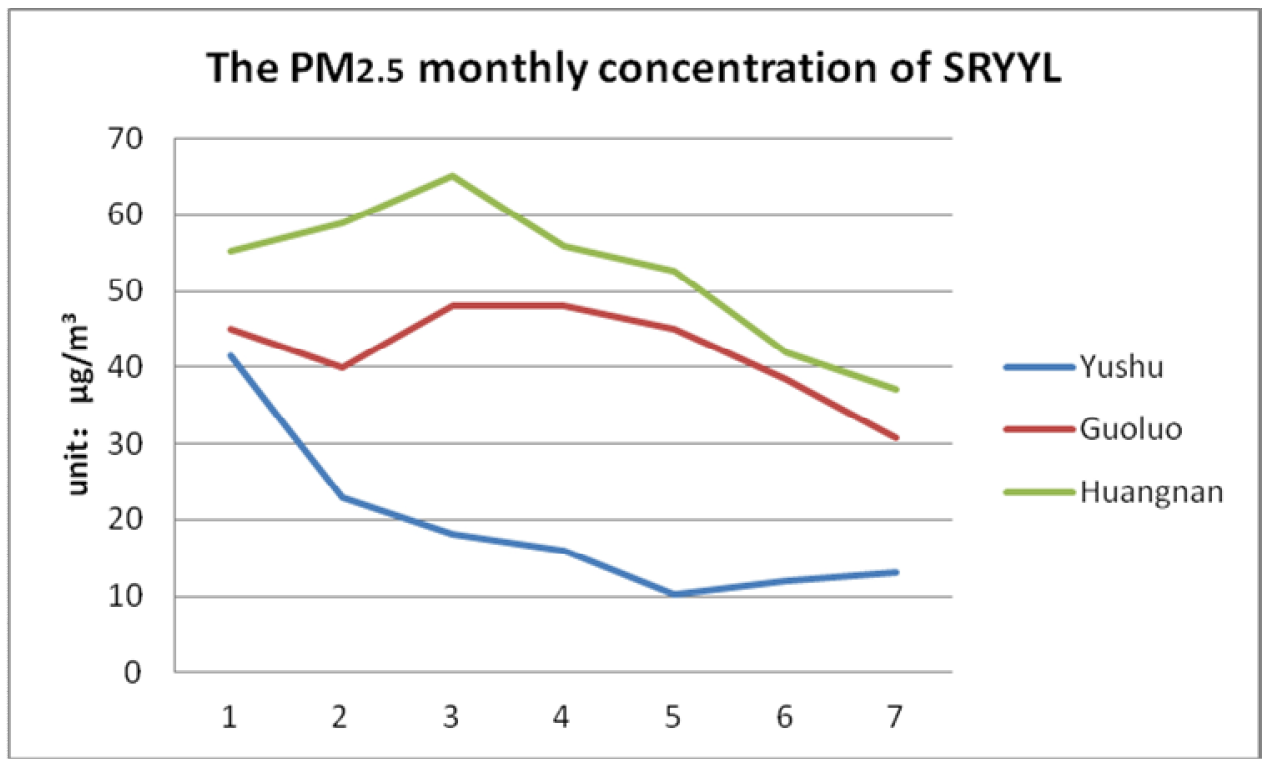

Fig.6 The $\mathrm{PM}_{2.5}$ monthly concentration of SRYYL

The $\mathrm{PM}_{2.5}$ concentration shows the same rule as the $\mathrm{PM}_{10} \mathrm{In}$ Winter and spring monthly concentration of the three state were higher than any other months. In the three states, Huangnan State's concentration is the highest. They all decrease from April and reach the lowest point during June and July and they all lower than the nation standard.

\section{Summary}

1. The variation pattern of $\mathrm{SO}_{2}$

According to the analysis, we obtained that the concentration of $\mathrm{SO}_{2}$ have no significant change during the period, and was influenced by meteorological factor. Specially, it was hig her in first quarter. The range of concentration was $30 \mu \mathrm{g} / \mathrm{m}^{3}-41 \mu \mathrm{g} / \mathrm{m}^{3}$. Therefore, it was low er in third quarter and the range of concentration was $21 \mu \mathrm{g} / \mathrm{m}^{3}-23 \mu \mathrm{g} / \mathrm{m}^{3}$. The concentration of $\mathrm{SO}_{2}$ showed decrease trend.

2. The variation pattern of $\mathrm{NO}_{2}$

According to the analysis, the concentration of $\mathrm{NO}_{2}$ changed as $\mathrm{SO}_{2}$ but the concentratio $\mathrm{n}$ of $\mathrm{NO}_{2}$ is lower.

3. The variation pattern of $\mathrm{CO}$

According to analyze, we obtained that the concentration of $\mathrm{CO}$ won't changed much, an $\mathrm{d}$ it was influenced by meteorological factors, especially, it was higher in first quarter. The concentration of $\mathrm{CO}$ showed decrease trend.

4. The law and variation of $\mathrm{O}_{3}$

According to the analysis, we obtained that the concentration of $\mathrm{O}_{3}$ showed increase tren $\mathrm{d}$ and it was influenced by meteorological factors, especially, it was higher in third quarter.

5. The law and variation of $\mathrm{PM}_{10}$ and $\mathrm{PM}_{2.5}$

According to the analysis, it obtained that the concentration of $\mathrm{PM}_{10}$ and $\mathrm{PM}_{2.5}$ have simi lar variation patterns, and it was influenced by meteorological factors, especially, it was hig her in first quarter. The concentration of $\mathrm{PM}_{2.5}$ and $\mathrm{PM}_{10}$ showed decrease trend. 


\section{Acknowledgement}

This study was supported by grants from the National Key Technology R\&D Program of Q inghai province 《source apportionment of atmospheric particulates $\mathrm{PM}_{2.5}$ in Xining》. (2013 $-\mathrm{J}-101$ )

This study was supported by grants from the project for young scientists fund of Qinghai $p$ rovince 《Plateau is a typical city motor vehicle exhaust emissions of volatile organic comp ounds characteristic spectrum》. (2015-ZJ-950Q)

This study was supported by grants from The innovation team Program of Qinghai province $\left\langle\mathrm{PM}_{2.5}\right.$ automatic monitoring method in plateau area $\rangle$. (2015-ZJ-914)

This study was supported by National Station for Background Atmospheric Monitoring, Men yuan, Qinghai, China

This study was supported by the program of highland of talent of Qinghai province.

The contents of this paper are solely the responsibility of the authors and do not necessaril y represent official views of the sponsors.

\section{References}

[1] Holloway T, Fiore A, Hastings MG. Intercontinental transport of air pollution: will emer ging science lead to a new hemispheric treaty? Environ Sci Technol. 2003 Oct 15; 37(2 $0): 4535-42$.

[2] DJ, Lei H, Lin. Intercontinental transport of aerosols and photochemical oxidants from Asia and its consequences. Wuebbles. J. Environ Pollut. 2007 Nov; 150(1):65-84. Epub 2007 Aug 22. 